\title{
ALIMENTAÇÃO DA CRIANÇA COM FISSURA DE LÁBIO E/OU PALATO - UM ESTUDO BIBLIOGRÁFICO
}

\author{
Raimunda da Costa Araruna* \\ Dulce Maria Silva Vendrúscolo**
}

ARARUNA, R.C.; VENDRÚSCOLO,D.M.S. Alimentação da criança com fissura de lábio e/ou palato - um estudo bibliográfico. Rev.latino-am.enfermagem, Ribeirão Preto, v. 8, n. 2, p. 99-105, abril 2000.

O objetivo deste estudo é descrever a criança portadora de deformação congênita lábio palatal, enfatizando sua alimentação, as dificuldades e os métodos alternativos para alimentar a criança, e assistência de enfermagem neste processo. A revisão bibliográfica nos revela que são muitos os aspectos envolvidos no cuidado da alimentação da criança fissurada, envolvendo relações complexas de caráter afetivo, social, econômico e cultural, que influenciam na relação mãe-filho, na discriminação social da criança fissurada, na dificuldade da mãe para alimentar e cuidar dessa criança. A revisão efetivada reforça a implementação do aleitamento materno, resguardando os limites fisiológico, psicológico, sociais, que envolvem a criança e a sua família, e a importância da alimentação para o desenvolvimento fisico e emocional favorecendo a correção cirúrgica das fissuras de lábio elou palato e o seu processo de reabilitação.

UNITERMOS: alimentação, criança, fissura lábial, fissura palatina

\section{1 - INTRODUÇÃO}

A assistência à criança, em sua fase de desenvolvimento e crescimento, necessita de constante suporte nutritivo, emocional e intelectual. As crianças que nascem com fissuras de lábio e/ou palato sofrem interferência em sua capacidade natural de ser adequadamente alimentadas e apresentam aspectos negativos em sua evolução normal.

Portanto, o tratamento visando os aspectos evolutivos destas crianças tem como princípio garantir nutrição, estimulação neurossensorial e harmonia no meio familiar, através de apoio e orientação aos pais com relação a particularidade de seus filhos, para que, com o devido conhecimento, aceitem a situação e possam efetivar as medidas indicadas pela equipe multidisciplinar, necessárias ao tratamento requerida principalmente nos primeiros anos de vida.

Segundo ALTMANN et al. (1997), a alimentação oral deve ser estimulada precocemente, ou seja, logo após o nascimento, acompanhada por nutricionistas, enfermeiras, neonatologistas, fonoaudiólogos, e outros membros da equipe; esses cuidados vêm aumentar as chances de sucesso de se alcançar as melhores condições de vida possíveis, possibilitando que, mais brevemente, as intervenções corretivas sejam realizadas com êxito, evitando futuras complicações.

A complexidade do contexto em que se insere o recém-nascido portador de fissura labial e/ou palatal exige de todos, familiares e profissionais da saúde envolvidos na assistência a criança portadora de fissura de lábio e/ ou palato, conhecimento, determinação, entendimento e paciência para que se possa alcançar o fim comum que é obter um indivíduo saudável, e integrado a sociedade (ALTMANN et al. ,1997).

No Brasil, a atenção especializada a essas crianças tem início a partir de 1967, quando o Hospital de Pesquisa e Reabilitação de Lesões Lábio-Palatais (HPRLLP) da Universidade de São Paulo, localizado na cidade de Bauru Estado de São Paulo, iniciou um trabalho de reabilitação da criança com fissura de lábio e/ou palato. Ao longo dos anos, essa instituição vem obtendo conquistas na assistência e pesquisa e no ensino nesta área (THOMÉ, 1990; SPERI, 1996).

$\mathrm{Na}$ literatura nacional e internacional, evidenciou-se que os autores consideram as fissuras de

\footnotetext{
* Docente da Universidade Federal do Acre - UFAC. Aluna do Curso de Especialização em Enfermagem Pediátrica e Neonatológica da Escola de Enfermagem de Ribeirão Preto da Universidade de São Paulo

** Docente da Escola de Enfermagem de Ribeirão Preto da Universidade de São Paulo. Membro do Grupo de Estudos em Saúde da Criança e do Adolescente

Resumo da Monografia: Conclusão do Curso de Especialização em Enfermagem Pediátrica e Neonatológica, Escola de Enfermagem de Ribeirão Preto da Universidade de São Paulo, 1997
} 
lábio e/ou palato, uma malformação congênita de elevada incidência, sendo atribuídas a fatores genéticos e ambientais, que podem atuar isolados ou em associação. Dentre os fatores ambientais, destacam-se os nutricionais, infecciosos, psíquicos, radiação, idade da mãe, uso de drogas e outros agentes químicos. A hereditariedade sendo responsável por $25 \%$ a $30 \%$ dos casos de fissuras de lábio e/ou palato cerca de $70 \%$ a $80 \%$ dos casos são considerados de etiologia multifatorial. Essas são consideradas como sendo a segunda malformação mais comum na população. No Brasil, ainda não é possível saber o número exato de fissurados, estima-se existirem cerca de 180.000 portadores, sendo a ocorrência da ordem de um para cada 650 nascimentos, e a mortalidade no primeiro ano de vida em torno de 35\% (LOFFEDO, 1990; THOMÉ, 1990).

\section{OBJETIVO}

O objetivo deste trabalho é a partir de dados da literatura descrever a alimentação da criança portadora de deformação congênita de fissura de lábio e/ou palato, e as dificuldades e métodos alternativos empregados nesse processo.

\section{2 - A CRIANÇA PORTADORA DE FISSURA DE LÁBIO E/OU PALATO}

Segundo ALTMANN et al. (1997) o desenvolvimento da face humana decorre precisamente entre a $4^{\mathrm{a}}$ e $8^{\mathrm{a}}$ semana de fecundação. Para que isso ocorra torna-se necessário uma coordenação de proliferação celular, interação, diferenciação e migração, as quais culminam com a formação dos processos faciais e a definição morfológica da face. A face humana é formada pelo crescimento e união de dois processos bilaterais separados: os processos maxilares e mandíbulares, e um processo fronto nasal, que originará os processos nasais mediais e laterais. As fissuras são resultados da falta de coalescência desses processos.

Várias são as classificações utilizadas para as fissuras labiopalatinas; entretanto, a mais utilizada pelos profissionais é a classificação de SPINA et al. (1972). Esta classificação utiliza como ponto de referência o forame incisivo, limite entre palato primário e o secundário (pró-lábio, pré-maxila e septo cartilagionoso), separando as fissuras labiopalatinas em três tipos principais:

1 - Fissura pré-forame incisivo: são as fissuras labiais unilateral, bilateral e mediana.

2 - Fissura pós-forame incisivo: são fissuras palatinas, em geral medianas, que podem situar-se apenas na úvula, palato e envolver todo palato duro.

3 - Fissuras transforame incisivo: são os de maior gravidade, unilaterais ou bilaterais, atingindo lábio, arcada alveolar e todo palato.

A alimentação do fissurado labiopalatino é muitas vezes difícil, sobretudo quando a família ainda não foi orientada. Os problemas mais comuns são sucção inadequada por falta de pressão intra-oral; tempo de mamada prolongada e regurgitação. $\mathrm{O}$ aconselhamento precoce sobre as melhores técnicas alimentares mostra que os filhos de famílias bem orientadas crescem mais, alimentam-se mais facilmente, e que a ansiedade dos pais é menor.

A criança portadora de fissura pré-forame incisivo não têm problemas alimentares, mas aquelas com fissuras pós-forame ou transforame incisivo, podem apresentar dificuldades alimentares por não conseguirem uma pressão intra-oral adequada.

A sucção insuficiente, os vômitos e os engasgos ocorrem nos casos de orientações inadequadas à mãe, quanto ao melhor método de alimentar o recém-nascido portador de fissura de labiopalatina. $\mathrm{O}$ recém-nascido que não apresenta outras deformações congênitas associadas à fissura, tem boa movimentação mandibular e, apesar da pouca pressão intraoral, tem inclusive condições de sugar o peito materno (THOMÉ, 1990; ALTMANN et al., 1997).

O recém-nascido portador de fissura labial cria um trauma mais imediato nos pais do que aquele portador apenas de fissura palatina. Assim sendo, implicações psicológicas para as crianças portadoras de fissuras de lábio e/ou palato, podem originar-se logo após o nascimento, dependendo da forma como a criança é recebida no meio familiar. As primeiras preocupações da família, no cuidado incluem a sobrevivência da criança e sua alimentação e a deformidade estrutural. Mais tarde, aparecem aspectos relativos a ortodontia, fala, audição e aparência pessoal. Essas dificuldades poderão interferir no desenvolvimento global da criança nos dois primeiros anos de vida.(SANTOS et al., 1980).

A dificuldade de alimentar a criança portadora de fissura de lábio e/ou palato interfere fundamentalmente neste processo, uma vez que a correção cirúrgica da anomalia, geralmente depende do estado nutricional e do seu desenvolvimento físico.

\section{3 - ALIMENTAÇÃO DA CRIANÇA COM FISSURA DE LÁBIO E/OU PALATO}

Em decorrência do rápido crescimento durante o primeiro ano de vida, a infância é um dos períodos 
mais críticos do ciclo da vida, dessa forma o alimento e a nutrição são essenciais ao processo de desenvolvimento da criança.

Diversos autores (LAURENCE, 1980; BACHEGA et al., 1983; THOMÉ, 1990; SPERI, 1996; ALTMANN et al., 1997), são unânimes em considerar que os primeiros cuidados com o recém-nascido trazem para a mãe uma certa insegurança, sobretudo no que se refere à alimentação. Alimentar uma criança recémnascida com deformação de lábio e/ou palato torna-se um processo estressante e difícil, tanto para mãe como para a criança, contribuindo para isso a angustia, ansiedade e o medo de manusear o bebê.

ZICREFOOSE (1957) estudou 58 famílias, observando as formas de alimentar as crianças fissuradas. Esta observação revelou para o autor a criatividade e o emprego de várias técnicas para conseguir alimentar seus filhos, melhorar a capacidade de sucção, deglutição e a mastigação dos alimentos, prevenindo o engasgo. Alguns pais preferiram alimentar os recém-nascidos por sonda nasogástrica; os que alimentavam com mamadeira mostravam-se aflitos devido a demora e aumentar o furo do bico amenizava sua aflição; colocar o bico no lado não fissurado melhorava a sucção e deglutição; ensinar as crianças maiores mastigar lentamente e selecionar os alimentos de difícil digestão como as frituras melhoravam a sua alimentação. Estes procedimentos amenizavam a aflição dos pais e contribuíam para melhor ajustamento da criança.

PARADISE \& MC WILLIANS (1974), afirmam que as dificuldades de sucção e deglutição muitas vezes podem levar ao agravamento do estado nutricional da criança fissurada, devido à incapacidade ou insuficiência da sucção, e problemas pulmonares, decorrentes da aspiração de alimentos, resumindo esquematicamente nos dados apresentado na Figura 1 estas dificuldades e complicações que decorrem do processo alimentação e nutricional dessa criança, levando às condições desfavoráveis de saúde.

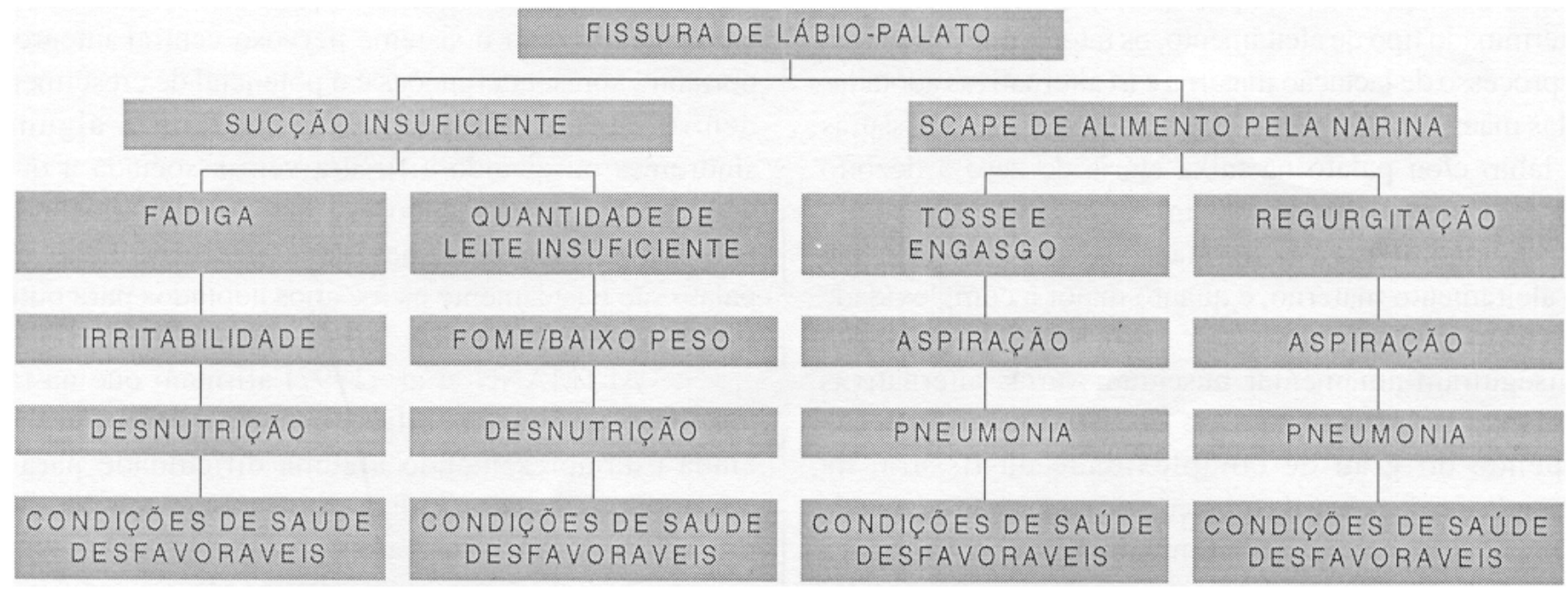

Fonte: PARADISE, L.; MC WILLIAMS, B.J. Simplified felder for infants with eleft palate. Pediatrics, v. 53, n. 4, p. 566-568, 1974

\section{Figura 1}

Para evitar complicações no processo de alimentação do lactente fissurado, algumas recomendações são apontadas como: manter a criança sempre seca e confortável; lavar as mãos; fazer higiene oronasal com cotonete molhado em água fervida, antes e depois da alimentação, para que se evite a permanência de resíduos e partículas de leite na região, e evitar infecções; .manter a criança em posição semi-sentada ao oferecer alimentos para evitar aspiração; fazer pausas durante a mamada para que a criança eructe; não se deve evitar o lado da fissura, e sim proporcionar estímulos através do contato com o bico do seio ou da mamadeira para exercitar a musculatura afetada; após as mamadas, colocar a criança em decúbito lateral, diminuindo assim, o risco de asfixia, pois apesar da eructação, há risco de refluxo pela narina, de parte do leite ingerido; ter tranqüilidade, pois cada mamada pode durar de 30 a 40 minutos.

\section{1 - Aleitamento materno}

A primeira orientação dada às mães é com relação ao aleitamento materno. Todavia cabe lembrar, que a maioria das crianças não conseguem o suprimento necessário só com o aleitamento natural. Assim, recomenda se colocar o recém nascido por cinco minutos em cada seio para estimular a descida do leite e para reforçar o contato mãe-filho. Após este tempo, deve-se 
oferecer o leite ordenhado em mamadeira com bico ortodôntico e furo para cima.

Diversos autores (LAURENCE, 1980; THOMÉ et al., 1980; THOMÉ, 1990; SPERI,1996), afirmam que o recém-nacido fissurado pode e deve ser levado ao peito materno pois este contato mãe-filho é de suma importância para o equilíbrio emocional. $\mathrm{O}$ aleitamento natural é possível em crianças com fissura de lábio e/ou palato, sendo que a técnica da alimentação vai depender da complexidade da fissura e condições da criança. $\mathrm{O}$ aleitamento materno, embora mais trabalhoso que a mamadeira é recomendado pelo seu valor nutritivo e qualidade antibacteriana, auxiliando na prevenção de infeções, sobretudo a do ouvido médio, comuns nos portadores dessa malformação.

THOMÉ (1990) em um estudo realizado no Hospital de Pesquisa e Reabilitação de Lesões LábioPalatais da USP, avaliou a situação do aleitamento materno em crianças portadoras de fissuras orais segundo o tipo de fissura, o tipo de aleitamento, as informações verbalizadas pelas mães, para justificarem a opção para determinado tipo de aleitamento, os fatores que interferem no processo de lactação materna e as alternativas adotadas pelas mães para alimentar crianças portadoras de fissuras de lábio e/ou palato na faixa etária de zero a dezoito meses. Os resultados desta investigação permitiram a autora concluir que a malformação lábio-palatal interfere no aleitamento materno, e quanto maior a complexidade da fissura, mais precoce o desmame. Aquelas que conseguiram amamentar buscaram várias alternativas para esta prática. $\mathrm{O}$ sucesso do aleitamento materno depende do grau de complexidade da fissura, da estimulação da mãe e da criança e da adaptação adequada desta ao processo do aleitamento. As considerações apresentadas nesta pesquisa vêm confirmar as observações apresentados no final da década de 50, por ZICREFFOOSE (1957).

Ressaltando a importância da mãe no processo de alimentar seu filho, quando não se consegue aleitamento materno através de sucção no peito da mãe, a orientação é para ordenhar o leite e oferece-lo à criança em mamadeira, isto não sendo possível, outro leite lhe deve ser-lhe oferecido, também em mamadeira. Apesar desta recomendação, existem várias situações que impedem o aleitamento materno portanto, vai depender das condições da criança, da mãe e de fatores emocionais e sociais que possam interferir neste processo.

\section{2 - Alimentação na mamadeira}

Segundo ALTMANN et al. (1997) o crescimento e o desenvolvimento normal da face podem ser prejudicados pela forma dos bicos de mamadeira utilizados, por não serem desenhados de acordo com a fisiologia do aleitamento. Alguns cuidados devem ser tomados na escolha de um bico adequado como: comprimento, flexibilidade, tamanho do furo e posição adotada na cavidade oral. O bico da mamadeira deve ter um comprimento tal que não interfira na direção do crescimento da face. Bicos longos demais podem interferir no desenvolvimento facial. Devem ser flexíveis o suficiente para permitirem fácil adaptação na boca da criança e o furo deve permitir um adequado fluxo de leite.

Desta forma, o uso de um bico inadequadamente leva os lábios a adotarem uma posição invertida, causando enfraquecimento muscular e forçando a língua a moverse para frente mais do que para trás durante a sucção, prejudicando o desenvolvimento facial e dentário. Assim como qualquer criança normal, a criança portadora de fissura labiopalatina possui o reflexo de sucção preservado e deve ser exercitado plenamente. É importante orientar os pais a não superprotegerem seus filhos e a introduzirem gradativamente os alimentos pastosos e sólidos na dieta.

É importante salientar que a criança com fissura labiopalatina, tem o sistema nervoso central integro e, portanto, apresenta funções e o potencial de crescimento dentro da normalidade; excessão feita a algumas síndromes ou quando a fissura vem associada a outra deformação. Assim sendo, os métodos de alimentação necessários para recém-nascido com fissura lábio e/ou palato são basicamente os mesmos adotados para outros recém-nascidos normais.

ALTMANN et al. (1997) afirmam que na fase inicial, e somente nesta fase, quando o recém nascido ainda está apresentando alguma dificuldade para se adaptar à mamadeira, indica-se manobras que facilitem o escoamento de leite para a cavidade oral, as quais estimulam o recém-nascido a desencadear a sucção tais como: apertar o frasco da mamadeira de plástico; apertar levemente o próprio bico da mamadeira nas laterais; pressionar o bico da mamadeira sobre a língua de forma a provocar o abaixamento da mandíbula; puxar levemente o bico da mamadeira para fora da boca; fazer pressão externa nas bochechas da criança, assim como embaixo de sua mandíbula. Esta última manobra ajuda inclusive a melhorar o vedamento labial.

PARADISE \& MC WILLIAMMS (1974) ressaltam que manobras facilitadoras devem ser abandonadas logo que o profissional tenha feito a escolha do bico da mamadeira, adequado à força de sucção de recém-nascido, como à espessura do leite. Esta indicação ocorre normalmente durante as primeiras semanas de vida.

Para alguns autores os bicos de mamadeira mais adequados são os ortodônticos por serem curtos e anatômicos. $\mathrm{O}$ furo deve ser graduado de acordo com o poder de sucção de cada criança, sendo um tamanho 
regular usualmente indicado para intensificar o movimento de sucção. O bico é posicionado na região anterior da boca com o furo voltado para cima de forma similar ao posicionamento do peito materno na cavidade oral da criança. Com o furo nessa posição não é direcionado para a cavidade nasal devido à postura vertical que favorece a ação da força gravitacional (ALTMANN et al., 1997).

Não existe mamadeira especial para alimentação da criança portadora de fissura, mas sim uma adaptação com bico ortodôntico e com válvula que favorece a sucção e posicionamento dos órgãos fonoarticulatórios. Estudos
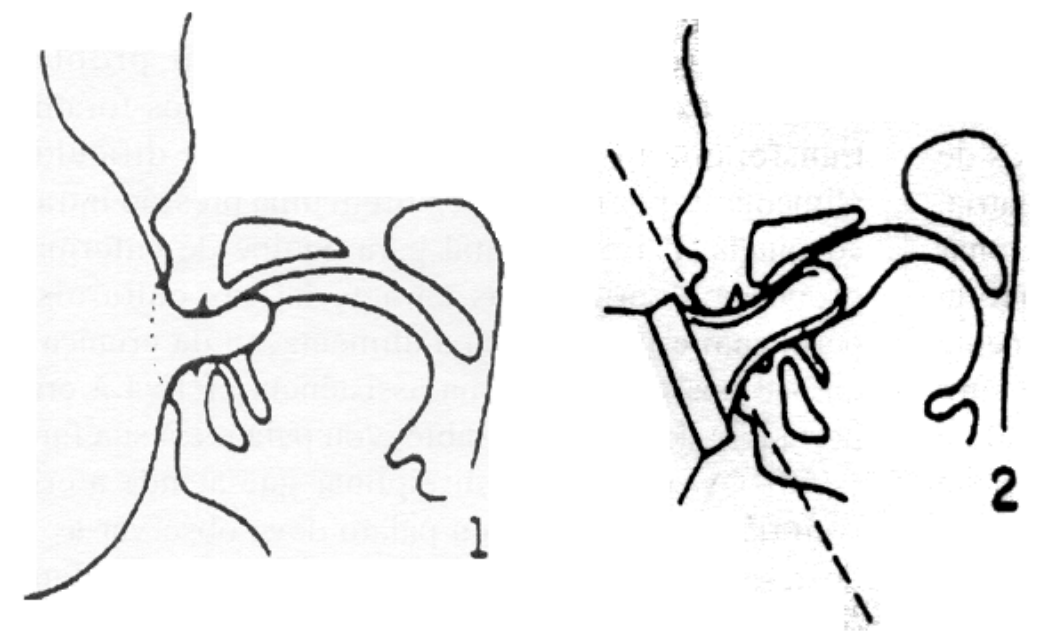

cinefluográficos mostram a semelhança do posicionamento dos órgãos fonoarticulatórios, tanto na amamentação ao seio materno, quanto na sucção do bico ortodôntico, favorecendo a mesialização da mandíbula em relação ao maxilar, devido aos movimentos de amplitude para a retirada do leite, com os lábios funcionando como um esfíncter. O bico ortodôntico deve estar sempre formando um ângulo de $90^{\circ}$ em relação à face, isso devido ao furo que é para cima, forçando a sucção ser eficiente (KUDO et al.,1980). O processo de sucção através do (a) seio materno, (b) do bico de mamadeira e (c) bico ortodôntico é melhor esclarecido na Figura 2.

Fonte: KUDO, A.M. et al. Ações integradas de fisioterapia, fonoaudiologia e terapia ocupacional em pediatria. In: SANTOS, A.E. Fisioterapia, fonoaudiologia e terapia ocupacional. São Paulo: Sarvier, 1980. v. 32

\section{Figura 2}

Outras técnicas de alimentação são introduzidas como métodos alternativos para garantir o desenvolvimento e crescimento normal da criança, sendo a mamadeira o mais utilizado (THOMÉ et al.,1980; BACHEGA et al.,1983; THOMÉ, 1990).

\section{3 - Alimentação por sonda nasogástrica}

As crianças portadoras de fissura de labiopalatina nascida a termo e sem nenhuma outra anormalidade associada podem ser alimentadas normalmente desde as primeiras horas de vida, não necessitando do uso de sondas nasogástricas.

As primeiras horas de vida representam um período importante para adaptação do reflexo de alimentação. Assim, se a criança fissurada for bloqueada através do uso de sonda após o nascimento, os seus mecanismos próprios para realizar os movimentos de sucção e deglutição serão prejudicados.

Portanto, as experiências de vida dessas crianças passam a ser diferentes das crianças normais. Isso significa que a criança não se utiliza de sucção para se alimentar, limitando sua participação ativa no processo deglutição. A alimentação por sonda nasogastríca (SNG) em crianças portadoras de fissuras de lábio e/ou palato é uma experiência desagradável e desconfortável, tanto para mãe, como para a criança, especialmente durante os primeiros meses, sendo vários os fatores que interferem no processo de alimentar a criança por SNG e no relacionamento da mãe com o filho (ZICREFOOSE, 1957; SANTOS et al., 1980; THOMÉ, 1990).

Do ponto de vista fisiológico, é importante para o recém-nascido iniciar a alimentação láctea por via oral, pois embora a quantidade de leite materno ingerido nos primeiros dias possa ser pequena, ela é capaz de preparar a fase oral da digestão, isso porque a ação da lipase pancreática é mínima no recém-nascido, entretanto, as lipases linguais são vitais para a quebra de triglicerídes, auxiliando no processo inicial da digestão. Alimentar o recém-nascido precocemente por sonda nasogástrica (SNG) interfere tanto na digestão como no próprio processo de alimentação, pois a interposição da sonda na narina, atua como um fator desconfortante provocando obstrução nasal, dificuldade para fechamento adequado da boca, comprometimento da sensibilização da cavidade 
oral; a alimentação oferecida em intervalos regulares pela SNG não prioriza o controle da fome, da saciedade e do volume alimentar (LAURENCE, 1980; ALTMANN et al., 1997).

\section{5 - Um método alternativo - alimentação por xícara}

Métodos artificiais de alimentação infantil, tais como cuias, xícaras com abas, bicos tipo bule e mamadeiras existem desde épocas pré-históricas. Embora muitos destes artefatos tenham desaparecidos, as mamadeiras e bicos dominaram a cultura ocidental nos últimos anos, fazendo que outros métodos sejam pouco considerados como, por exemplo, o uso da xícara. A alimentação através de xícara é utilizada em muitos países em desenvolvimento como um fator cultural, não apenas por mães que têm dificuldades de acesso a serviços de saúde, mas também nas unidades neonatais e de pediatria. Sua função primária e mais importante é proporcionar um método artificial seguro, até que a criança esteja forte e/ou madura, o suficiente para mamar exclusivamente no peito. Uma outra função importante da xícara é evitar o uso da mamadeira, fator de aumento da morbidade e mortalidade, particularmente nos locais em que a higiene é precária, a esterilização de mamadeiras é difícil, e as sondas gástricas não estão facilmente disponíveis. Nestes ambientes, a xícara proporciona um método de alimentação simples, prático e barato. Além disso, a alimentação com xícara proporciona o contato entre a mãe e o filho familiarizando o recém-nascido com o peito, permitindo-o experimentar pequenas quantidades de leite ordenhado manualmente (LAURENCE, 1980).

O tempo gasto na alimentação com xícara pode variar tanto quanto a alimentação com mamadeira ou sonda gástrica. Em situações onde se necessita de uma alternativa à mamadeira ou à sonda gástrica, a alimentação com xícara proporciona uma solução simples e afetiva. Ela oferece benefícios potenciais porque não é invasiva e o bebê pode regular sua própria ingesta quando a xícara é mantida, de maneira que o leite somente toque seus lábios e não seja despejado dentro da boca. Além disso, como a regulação de lambida/tragada é dependente exclusivamente do bebê, a respiração torna-se mais fácil de ser controlada e a deglutição ocorre quando o bebê está apto para essa função. Como resultado, evita-se a aspiração, tão comum entre as crianças portadoras de fissuras de lábio e/ou palato.

A alimentação com xícara é um método alternativo que amplia as opções disponíveis, tanto aos pais quanto aos profissionais, os quais podem necessitar de métodos não convencionais para solucionar situações difíceis de alimentação, e que segundo LAURENCE (1980) deve ser seriamente levada em consideração para uso em unidades neonatais e de cuidados intermediários, considerando que o método estreita a relação mãe e filho, o seu custo é bem menor, comparado com outros métodos alternativos.

\section{5 - CONSIDERAÇÕES FINAIS}

É possível considerar que a criança portadora de fissura pré-forame incisivo não têm problemas alimentares, mas aquelas com fissuras pós-forame ou transforame incisivo, podem apresentar dificuldades alimentares por não conseguirem uma pressão intra-oral adequada. É fundamental para equipe de enfermagem procurar identificar as características culturais que permeiam e influenciam a alimentação da criança para que se possa prestar uma assistência efetiva à criança portadora de fissura de lábio e/ou palato e à sua família.

A equipe multidisciplinar que atende a criança com fissura de lábio e/ou palato deve observar as fases do desenvolvimento bio-psico-social e o contexto familiar que está inserida, objetivando uma assistência humana e eficiente por parte da enfermagem e dos demais profissionais. O conhecimento sobre a fisiologia, o tratamento clínico e cirúrgico, não basta para apoiar uma proposta mais efetiva de assistência a estas crianças. Essa criança apresenta alterações no processo de sucção e deglutição, requerendo portanto, cuidados especializados durante a amamentação e outras formas alternativas de alimentação.

Os aspectos envolvidos nos cuidados da alimentação da criança fissurada, abrangem situações complexas, que envolvem relações sociais, afetivas, econômicas e culturais, além das dificuldades anatômicas. É necessário conhecer outros fatores que implicam na relação afetiva entre mãe- filho, na discriminação social da criança mal formada, na dificuldade de alimentar e cuidar da criança.

A revisão efetuada, reforça a implementação do aleitamento materno, resguardando os limites fisiológicos, psicológicos e sociais, que envolvem a criança e sua família e a importância da alimentação para o seu desenvolvimento físico e emocional.

\section{ALIMENTATION OF CHILDREN WITH LIP-PALATE MALFORMATION: A BIBLIOGRAPHIC STUDY}

The present study aimed at describing the children with congenital lip-palate malformation, emphasizing their alimentation, such as the difficulties and alternative methods to feed these children and nursing care in this process. The bibliographic review 
showed that there are many aspects in the alimentation care to fissured children, involving complex affective, social, economic and cultural relations that influence in mother-child relationship, in social discrimination of the fissured children and in mothers' difficulty to feed and give care to the child. Authors found the need to implement breast feeding, pointing out the physiological, psychological and social limitations that involve the child and the family as well as the importance of alimentation to physical and emotional development, favouring the surgical correction of lips and/or palate fissures as well as the rehabilitation process.

KEY WORDS: alimentation, child, lip fissure, palate fissure

\section{ALIMENTACIÓN DEL NIÑO CON FISURA DEL LABIO Y/O EL PALADAR - UN ESTUDIO BIBLIOGRÁFICO}

El objetivo de este estudio es describir al niño portador de deformación congénita labio palatal, enfatizando en su alimentación, las dificultades y los métodos alternativos para alimentar el niño y la asistencia de Enfermería en este proceso. La revisión bibliográfica nos revela que son muchos los aspectos involucrados en el cuidado de la alimentación del niño con fisura, abarcando relaciones complejas de carácter afectivo, social, económico y cultural, que influencian en la relación madre-hijo; en la discriminación social del niño fisurado, en la dificultad de la madre para alimentar y cuidar de ese niño. La revisión realizada refuerza la implementación de la lactancia materna, resguardando los límites fisiológicos, psicológicos, sociales, pertinentes al niño y a su familia, como también en la importancia de la alimentación para el desarrollo físico y emocional favoreciendo la corrección quirúrgica de las fisuras de labio y/o paladar y el proceso de rehabilitación.

TÉRMINOS CLAVES: alimentación, niño, fisura de labio, fisura de paladar

\section{6 - REFERÊNCIAS BIBLIOGRÁFICAS}

01. ALTMANN, E.B.C. et al. Fissuras labiopalatinas. In: PACHI, P.R. Aspectos pediátricos. 4. ed Carapicuiba: Pró-fono Departamento Editoral, 1997.

02. BACHEGA, M.I. et. al. Manual de instrução alimentar para crianças portadora de fissura labio-palatal. Bauru: Hospital de Pesquisa e Reabilitação de Lesões Lábio Palatais/ Universidade de São Paulo, 1983.

03. KUDO, A.M. et al. (coord.) Ações integradas de fisioterapia, fonoaudiologia e ocupacional em pediatria. In: SANTOS, A.E. Fisioterapia, fonoaudiologia e terapia ocupacional. São Paulo: Sarvier, 1980. Cap. 32, p. 309-368.

04. LAURENCE, R.A. Breast feeding the infant with a problem. In: FILHO, E.M.R. et al. Breast feeding a guide for the medical profissional. Saint Louis: Mosby, 1980. p. 187-220.

05 LOFFEDO, M.C.L. Fissuras lábio -palatais: estudo caso-controle de fatores de risco. São Paulo, 1990. 129p. Tese (Doutorado) - Faculdade de Saúde Pública, Universidade de São Paulo
06. PARADISE, J.L.; MC WILLIAMS, B.J. Simplified felder for infants with cleft palate. Pediactrics, v. 53, n. 4, p. 566-568, 1974.

07. SANTOS, R. et al. O serviço social no processo de integração social do fissurado lábio-palatal. Rev.Bras.Reabil., v. 2, n. 5, p. 12, 1980.

08. SPERI, A.P.S.G. Disfagia e deficiência nutricional na criança com fissura lábio-palatal. Franca, 1996. 37p. Monografia (Curso de Especialização) - Universidade de Franca.

09. SPINA, V. et al. Classificação das fissuras lábiopalatinas. Sugestão de modificação. Rev. Hosp. Clin.Fac.Med.São Paulo, v. 27, p. 5-6, 1972.

10. THOMÉ, S. Estudo da prática do aleitamento materno em crianças portadoras de malformações congênita de lábio e/ou de palato. Ribeirão Preto, 1990. 245p. Dissertação (Mestrado) - Escola de Enfermagem de Ribeirão Preto, Universidade de São Paulo.

11. THOMÉ, S. et al. Reabilitação de lesões lábiopalatais: "uma experiência de enfermagem". Rev. Bras. Enfermagem, Distrito Federal, v. 33, p. 242-252, 1980.

12. ZICREFOOSE, M. Feeding propblems of chidren with cleft palate. Children, v. 4, p. 225-228, 1957.

Recebido em: 12.11 .1998

Aprovado em: 4.11.1999 